\title{
Population-based mammography screening programme should be rigorously evaluated
}

Hong Kong Med J 2018;24:428

DOI: 10.12809/hkmj187547

To the Editor-Screening programmes must be rigorously evaluated using epidemiological principles. Arguments put forward by Chow ${ }^{1}$ provide only part of the picture.

An implicit assumption underlying the concept of screening is that detection before symptoms develop leads to a more favourable prognosis because earlier treatment is more effective than treatment started later. This assumption has intuitive appeal but the concept of screening is not as straightforward as it may appear. Any standard textbook of epidemiology will caution that issues such as appropriateness and evaluation of the screening test, subsequent diagnosis and management, and associated risks or costs, need to be rigorously considered to achieve the best value in population health terms.

Hong Kong has never established a populationbased breast cancer screening programme. The Cancer Expert Working Group on Cancer Prevention and Screening (CEWG) regularly revisits the literature and has never claimed that screening is of little value. Neither has it ruled in or out the possibility of breast cancer screening for local women at average risk. The CEWG states that there is insufficient evidence to recommend for or against population-based mammography screening for local asymptomatic women at average risk. This is a prudent approach when countries like the United Kingdom, Switzerland, and France have a decreased passion for similar mass screening programmes..$^{2-4}$

Women and doctors alike should be aware of the potential risks and benefits of breast cancer screening. For women whose risk level is average or low but who nevertheless consider undergoing the procedure, the doctor has a duty of care to explain not only the pros but also the cons of the procedure, including the possibility of a false-positive result, overdiagnosis, and overtreatment. Development of a validated risk prediction tool for the local population, which has been commissioned by the Government and is ongoing, can be used to guide screening decisions and enable women and clinicians to make an informed choice.

Of equal importance is the need for all stakeholder groups to encourage women to adopt healthy lifestyle habits that protect against breast cancer development, such as avoiding alcohol consumption, engaging in moderate and vigorous physical activity, maintaining a healthy body weight and waist circumference, and breastfeeding for as long as possible ${ }^{5}$; as well as raising breast awareness and literacy so that women seek medical attention as soon as they notice any unusual breast changes.

\section{Declaration}

The author has no conflicts of interest to disclose.

TH Lam, MD

School of Public Health, Li Ka Shing Faculty of Medicine, The University of Hong Kong, Pokfulam, Hong Kong

*Corresponding author: regina_ching@dh.gov.hk (Dr Regina Ching)

\section{References}

1. Chow LC. Is now the right time to abolish breast cancer screening in Hong Kong? Hong Kong Med J 2018;24:216-7.

2. Marmot MG, Altman DG, Cameron DA, Dewar JA, Thompson SG, Wilcox M. The benefits and harms of breast cancer screening: an independent review. Br J Cancer 2013;108:2205-40.

3. Biller-Andorno $\mathrm{N}$, Jüni P. Abolishing mammography screening programs? A view from the Swiss Medical Board. N Engl J Med 2014;370:1965-7.

4. Barratt A, Jørgensen KJ, Autier P. Reform of the national screening mammography program in France. JAMA Intern Med 2018;178:177-8.

5. World Cancer Research Fund. Summary of conclusions. Available from: https://www.wcrf.org/sites/default/files/ Matrix-for-all-cancers-A3.pdf. Accessed 10 Jul 2018. 